\title{
User Assessment in Serious Games and Technology-Enhanced Learning
}

\author{
Francesco Bellotti, ${ }^{1}$ Bill Kapralos, ${ }^{2}$ Kiju Lee, ${ }^{3}$ and Pablo Moreno-Ger ${ }^{4}$ \\ ${ }^{1}$ Department of Naval, Electric, Electronic and Telecommunications Engineering, University of Genoa, \\ Via all'Opera Pia 11/a, 16145 Genoa, Italy \\ ${ }^{2}$ Faculty of Business and Information Technology, University of Ontario Institute of Technology, \\ 2000 Simcoe Street North, Oshawa, Canada L1H 7 K4 \\ ${ }^{3}$ Department of Mechanical and Aerospace Engineering, Case Western Reserve University, 10900 Euclid Avenue, \\ Cleveland, OH 44106, USA \\ ${ }^{4}$ Faculty of Computer Science, Universidad Complutense de Madrid, Ciudad Universitaria Universidad Complutense de Madrid, \\ 28040 Madrid, Spain
}

Correspondence should be addressed to Francesco Bellotti; franz@elios.unige.it

Received 12 February 2013; Accepted 12 February 2013

Copyright (C) 2013 Francesco Bellotti et al. This is an open access article distributed under the Creative Commons Attribution License, which permits unrestricted use, distribution, and reproduction in any medium, provided the original work is properly cited.

Games have always had a great relevance for humancomputer interaction, since they represent a computer application sector which involves a wide enthusiastic audience and has opened the way to new hardware and software tools (e.g., graphic boards, pointing and gesture-based devices, virtual worlds) that have then become common also in other application domains.

Nowadays, an emergent trend concerns serious games (SGs), games that have been designed and are used with a different purpose than pure entertainment [1-3]. SGs are becoming ever more appealing for education and training, and several research coordination initiatives have been undertaken recently, such as the Games and Learning Alliance (http://www.galanoe.eu/) (GaLA) EU FP7 Network of Excellence (NoE) [4] and the Serious Games Network (http://www.seriousgamesnet.eu/) (Segan) EU Lifelong Learning Programme (LLP) NoE. The main goal of these networks is to study SGs so that they can become an effective and reliable tool for education and corporate training. To this end, it is necessary to substantiate the growing interest and appeal of SGs within the scientific and education communities through the definition of proper principles and concrete tools, methodologies, and practices for design and deployment of SGs $[5,6]$.
Proper assessment of user performance and status is key for SGs with educational goals [7, 8]. An effective application of SGs for education and training demands appropriate metrics, tools, and techniques for user evaluation, in particular by measuring elements such as learning outcomes, engagement or gameplay performance $[9,10]$. These are data that are considered as necessary in order to show to the large public of families, teachers, instructors, and stakeholders the validity of SGs in education and training. Devices like stereo cameras, eye trackers, physiological, and neural response sensors, now available at reasonable prices, not only support innovative interactions, but also present opportunities to new user monitoring and evaluation.

Due to the complexity of human nature and individual differences, objective and systematic assessment of human behavior and performance remains highly difficult. In addition, data analysis and evaluation methods for technologyassisted learning and assessment are still underdeveloped because of different perspectives in evaluation. Thus, development of systems and tools able to support provision of effective feedback is a major requirement for a new generation of SGs. Breakthroughs in this area can be made by advancing issues including, but not limited to, an efficient and easy-touse user interface; effective data management; data analyses 
methods; sensor data fusion and integration; user feedback mechanism.

The goal of this special issue is to investigate user assessment in SGs, showing the state of the art and proposing advancements in some specific topics, with a special perspective on usability and usefulness for learning.

Our review process has led to the selection of six papers by authors of various cultural background and geographical provenance. L. Derbali and C. Frasson investigated motivational strategies (i.e., the use of game elements for providing motivational supports to users) and assessment of learners' motivation during serious games. They propose the use of physiological sensors-in particular they highlight the importance of monitoring the neural activity - to collect data for a theoretical model of motivation.

P. Moreno-Ger et al. propose a new method of usability assessment adhoc designed for SGs, which exploits large amounts of recorded gameplay data and also provides SG designers with suggestions on how to improve their design.

T. D. Parsons et al. investigated psychophysiological responses of test users in order to understand whether highly immersive virtual environments result in increased sensory arousal, obtaining results that suggest that higher fidelity scenarios have great efficacy related to sensory arousal.

K.-H. Huang et al. propose guidelines and research approaches for developing useful personas for large-scale service design and social interaction design. This is a useful advancement in user modeling and profiling, which is a fundamental step for user behaviors prediction.

A.G. Thin presents a real-world case study concerning the assessment of a virtualized-reality-based game for simultaneous rehabilitation of motor skill and confidence. We believe that this study is an interesting starting point for the development of a new generation of games for health that can be integrated in clinical environments and cases.

The special issue includes also a more general overview paper, written by the guest editors, which discusses the state of the art on assessment of SGs and in SGs. After a review of the literature on the educational effectiveness of SGs, the paper addresses how to assess the learning impact of SGs and methods for competence and skill assessment. Finally, it suggests directions for future research.

The guest editors are proud of presenting a balanced mix of papers, especially in terms of perspectives, approaches, and addressed topics. The selected papers show that the field of user assessment in serious games is advancing especially in the direction of a continuous in-game embedded (stealth) assessment, also exploiting neurophysiological signals. We believe that this, together with development of SG-tailored learning analytics, represents major innovation modules for new generation games, and innovative human-computer interaction solutions are to be developed in order to allow a confortable yet effective acquisition of inputs and provision of feedback.

\section{References}

[1] J. P. Gee, What Video Games Have to Teach Us About Learning and Literacy, Palgrave Macmillan, New York, NY, USA, 2003.

[2] M. Prensky, "Digital game-based learning," ACM Computers in Entertainment, vol. 1, no. 1, p. 21, 2003.

[3] F. L. Greitzer, O. A. Kuchar, and K. Huston, "Cognitive science implications for enhancing training effectiveness in a serious gaming context," ACM Journal on Educational Resources in Computing, vol. 7, no. 3, article 2, 2007.

[4] A. De Gloria, F. Bellotti, and R. Berta, "Building a comprehensive R\&D community on serious games," in Proceedings of the 4th International Conference on Games and Virtual Worlds for Serious Applications (VS-GAMES '12), Genova, Italy, October 2012.

[5] F. Bellotti, R. Berta, and A. De Gloria, "Designing effective serious games: opportunities and challenges for research," International Journal of Emerging Technologies in Learning, vol. 5, pp. 22-35, 2010.

[6] A. del Blanco, J. Torrente, E. J. Marchiori, I. Martínez-Ortiz, P. Moreno-Ger, and B. Fernández-Manjón, "A framework for simplifying educator tasks related to the integration of games in the learning flow," Journal of Educational Technology \& Society, vol. 15, no. 4, pp. 305-318, 2012.

[7] V. Shute, M. Ventura, M. Bauer, and D. Zapata-Rivera, "Melding the power of serious games and embedded assessment to monitor and foster learning: flow and grow," in Serious Games: Mechanisms and Effects, U. Ritterfeld, M. Cody, and P. Vorderer, Eds., Routledge, Taylor and Francis, Mahwah, NJ, USA, 2009.

[8] G. Bente and J. Breuer, "Making the implicit explicit: embedded measurement in serious games," in Serious Games: Mechanisms and Effects, U. Ritterfield, M. J. Cody, and P. Vorderer, Eds., Routledge, Taylor and Francis, Mahwah, NJ, USA, 2009.

[9] F. Bellotti, R. Berta, A. De Gloria, and L. Primavera, "Supporting authors in the development of task-based learning in serious virtual worlds," British Journal of Educational Technology, vol. 41, no. 1, pp. 86-107, 2010.

[10] T. M. Connolly, E. A. Boyle, E. MacArthur, T. Hainey, and J. M. Boyle, "A systematic literature review of empirical evidence on computer games and serious games," Computers \& Education, vol. 59, no. 2, pp. 661-686, 2012.

Francesco Bellotti Bill Kapralos Kiju Lee 

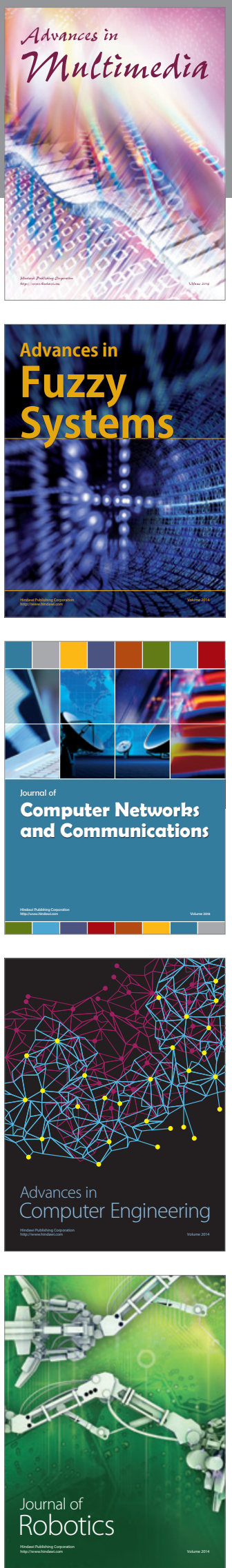

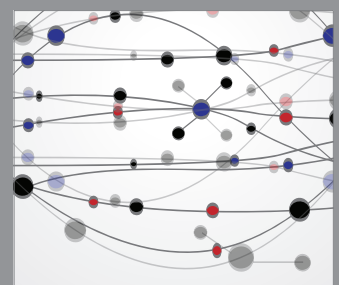

The Scientific World Journal
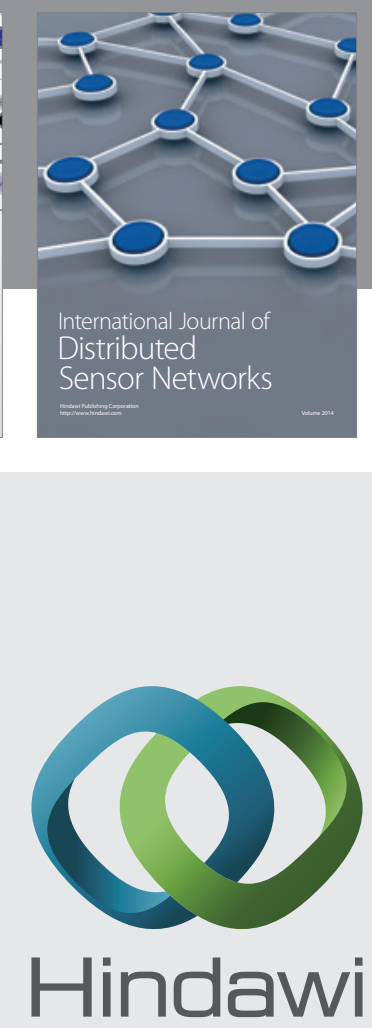

Submit your manuscripts at

http://www.hindawi.com
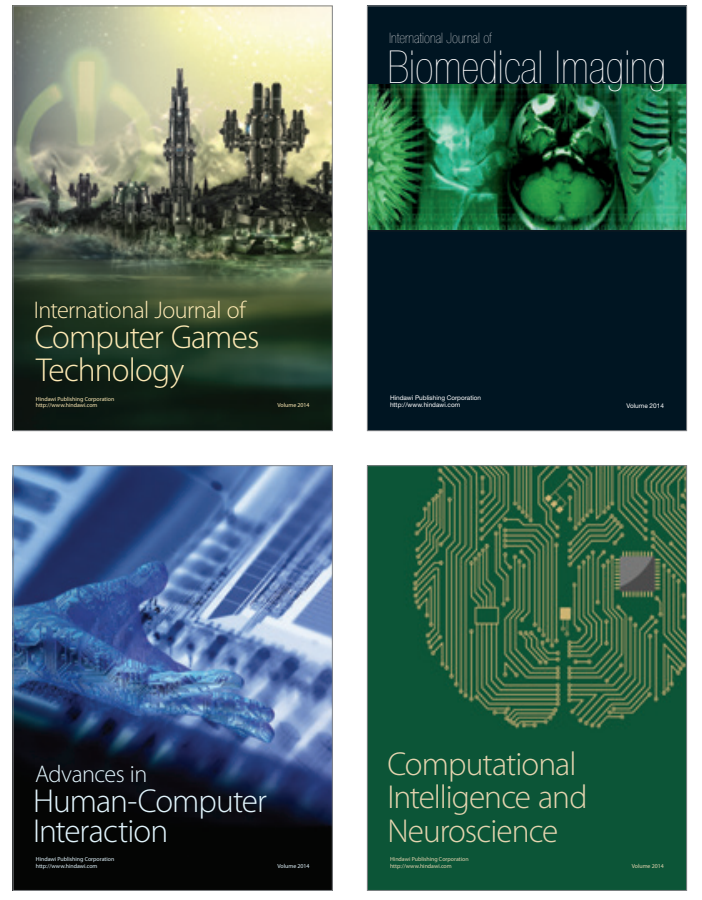
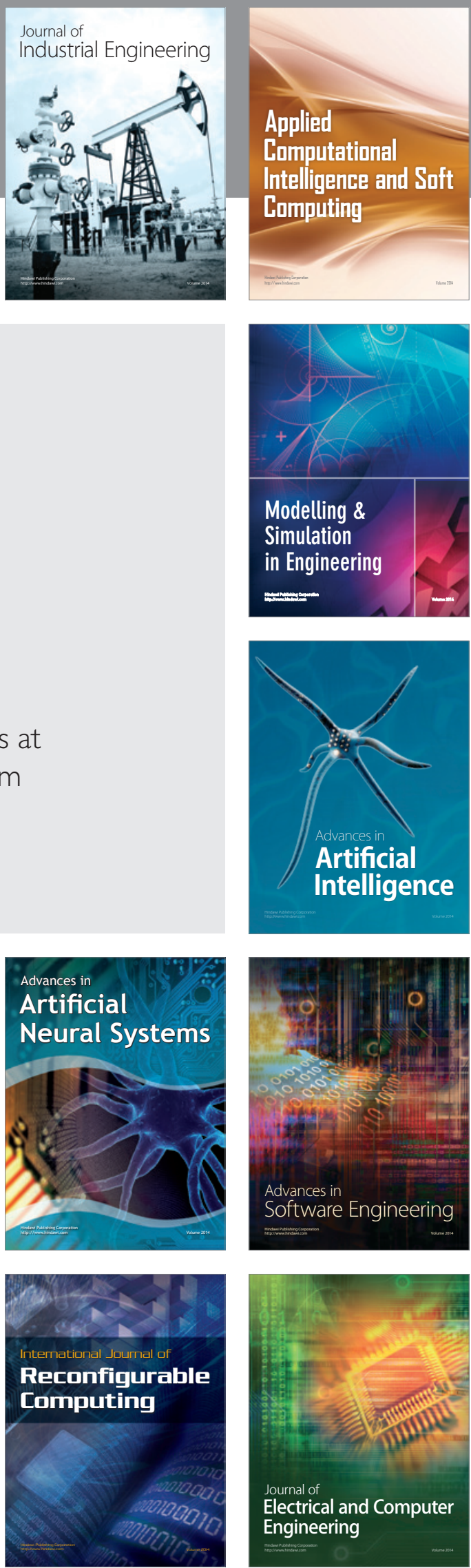